\title{
A EXTENSÃO UNIVERSITÁRIA E A PROMOÇÃO DA RESPONSABILIDADE SOCIOAMBIENTAL: Relato do PISC EM Santa Maria (RS)
}

\section{University extension and social-environmental responsibility promotion: report from Pisc, Santa Maria (RS)}

\section{La extensión universitaria y la promoción de la responsabilidad socioambiental: relato del Pisc en Santa Maria (RS)}

\author{
Maria Ivete Trevisan Fossá ${ }^{1}$ \\ Luciana Carvalho \\ Patrícia Milano Pérsigo ${ }^{3}$ \\ Camila Reck Figueiredo ${ }^{4}$
}

\begin{abstract}
RESUMO
O presente artigo reflete sobre a importância da inserção da universidade, por meio de práticas sociais e de comunicação, na agenda da responsabilidade socioambiental. É feito um relato de experiência do "Programa de inclusão social dos catadores de materiais recicláveis do Município de Santa Maria (RS) pela geração de trabalho e renda em economia solidária (Pisc)". O programa é desenvolvido por professores e alunos da UFSM como extensão universitária, em conjunto com outras instituições na cidade de Santa Maria. Com metodologia e avaliação participativas, busca-se a conscientização dos catadores e da sociedade de um modo geral quanto à importância da destinação adequada do lixo. Além do resgate da cidadania de parte dessa população, a articulação entre ensino, pesquisa e extensão na universidade e o envolvimento da instituição universitária com outros setores da sociedade promove, a longo prazo, a formação de uma consciência ambiental. Ao mesmo tempo, ajuda a legitimar o papel da universidade como promotora de responsabilidade social.
\end{abstract}

Palavras-chave: responsabilidade social; desenvolvimento sustentável; inclusão social; extensão universitária.

\section{ABSTRACT}

This paper aims to reflect about the importance of inserting the University, through social and communication practices, in the agenda of social-environmental responsibility. This study made a report about the experience of "Programa de inclusão social dos catadores de materiais recicláveis do Município de Santa Maria (RS) pela geração de trabalho e renda em economia solidária (Pisc)". The program is developed by Universidade Federal de Santa Maria's professors and students as a university extension and works together with other institutions of Santa Maria city. Through a participatory methodology and evaluation, this study seeks the awareness of scavengers and society about the importance of an adequate destination of garbage.

\footnotetext{
${ }_{1}$ Graduada em Comunicação Social e Administração pela UFSM. Mestre em Comunicação pela Umesp e Doutora em Administração pela UFRGS. Professora da UFSM, lotada no Departamento de Comunicação e com atuação na graduação em Comunicação Social e nos programas de pós-graduação em Comunicação e em Administração da UFSM. Curso de Comunicação Social, prédio 21, cidade universitária/UFSM - Camobi, Santa Maria/RS. Cep: 97015-900. Fone: (55) 3320-8491. E-mail: fossa@terra.com.br. Programa financiado pelo Fundo de Incentivo à Extensão (Fiex)/UFSM.

${ }^{2}$ Graduada em Comunicação Social, habilitação Jornalismo pela UFSM. Especialista em Projetos Sociais e Culturais pela UFRGS e em Comunicação Midiática pela UFSM. Mestre em Comunicação Midiática pela UFSM. E-mail: lucianamenezescarvalho@gmail.com

3 Graduada em Comunicação Social, habilitação Relações Públicas pela UFSM. Especialista em Marketing e Recursos Humanos pela Fames. Mestre em Comunicação Midiática pela UFSM. Professora substituta na Faculdade de Comunicação Social da UFSM. E-mail: patriciapersigo@gmail.com

${ }^{4}$ Graduada em Publicidade e Propaganda pela Unifra. E-mail: camilareckf@hotmail.com
} 
Besides the rescue of citizenship by this population, the articulation among teaching, researching and extension at the University and the involvement of this institution with other society sectors promote, in a long term, the formation of an environmental awareness. At the same time, it helps to legitimize the University role as a promoter of social responsibility.

Keywords: social responsibility; sustainable development; social inclusion; university extension.

\title{
RESUMEN
}

\begin{abstract}
Este artículo reflexiona sobre la importancia de incluir la universidad, a traves de las prácticas sociales y la comunicación, en el programa de responsabilidad social y ambiental. Hizo un informe la experiencia de "Programa de la Inclusión Social de Los Recolectores de Materiales Reciclables de la ciudad de Santa Maria (RS) por el trabajo y la generación de ingresos en la Economía Solidaria (Pisc)". El programa es desarrollado por profesores y estudiantes de la UFSM como extensión universitaria, junto con otras instituciones de la ciudad de Santa Maria. A través de la metodología y la evaluación participativa, tiene por objeto aumentar la conciencia de los colectores y la sociedad en general acerca de la importancia de destino adecuada de basura. Además de la recuperación de una parte de la ciudadanía de población, el vínculo entre educación, investigación y extensión en universidad y la participación de la institucións adaémica con otros sectores de la sociedad promueve la formación de largo plazo una conciencia ambiental. Mismo tiempo, contribuye a legitimar el papel de la universidad como promotora de la responsabilidad social.
\end{abstract}

Palabras clave: responsabilidad social; desarrollo sustentable; inclusión social; extensión universitaria.

\section{Introdução}

Apenas há algumas décadas a sociedade passou a debater as consequências dos usos inadequados dos recursos naturais e a buscar soluções para o problema do lixo que produz. Por serem essas questões relativamente recentes, as organizações, sejam públicas ou privadas, ainda carecem de reflexões acerca de práticas sustentáveis que busquem um equilíbrio entre o desenvolvimento econômico $e$ a preservação do meio ambiente.

Em muitos casos, são desenvolvidas ações isoladas, impulsionadas mais pelo modismo do tema da responsabilidade social. Faz-se necessária uma perspectiva interinstitucional $e$ interdisciplinar que envolva os possíveis beneficiados na elaboração, desenvolvimento $e$ avaliação dos projetos. A universidade, tendo no tripé ensino, pesquisa e extensão a base de sua missão na sociedade, e na articulação de diferentes campos de conhecimento um de seus pressupostos, configura-se como uma instituição-chave para o desenvolvimento de projetos que resultem na transformação de cenários. Com a ação de instituições de ensino, pode-se trabalhar em direção a mudanças de hábitos e atitudes, fomentando a formação de atores multiplicadores de uma consciência de responsabilidade social (FELIX, 2007).

A necessidade de legitimação da instituição universitária hoje passa por estratégias comunicacionais que justifiquem e expliquem perante a sociedade o seu papel de agente transformador por meio da conciliação de conhecimentos e da intervenção no ambiente. Ela tem a responsabilidade de agenciar as demandas $e$ as propostas de soluções que circulam em seu entorno, pautando-se em práticas dialógicas permanentes entre a comunidade universitária e a sociedade de um modo geral. À universidade cabe, ainda, o desafio de ajudar a romper com as críticas de instituição defasada, descompassada em relação ao ritmo das mudanças sociais. Para Berger e Luckmann,

[...] o significado de uma instituição baseia-se no reconhecimento social desta instituição como solução "permanente" de um problema "permanente" da coletividade dada (1985, p. 98). 
Em função disso, as práticas interdisciplinares $e$ interinstitucionais são as mais adequadas para o êxito das propostas de extensão das instituições de ensino.

$\mathrm{O}$ presente artigo reflete sobre a importância da inserção da universidade, por meio de práticas sociais e de comunicação, na agenda da responsabilidade socioambiental que tem pautado as organizações. Faz um relato de experiência do "Programa de inclusão social dos catadores de materiais recicláveis do Município de Santa Maria/RS pela geração de trabalho e renda em economia solidária (Pisc)" (FOSSÁ, 2006). O programa de extensão universitária é desenvolvido por docentes e discentes dos Cursos de Graduação em Comunicação Social - Relações Públicas, Publicidade e Propaganda e Jornalismo, Engenharia Civil, Engenharia Mecânica, Engenharia da Produção e Ciência da Computação da Universidade Federal de Santa Maria, em parceria com a Prefeitura Municipal de Santa Maria/RS e a Empresa Brasileira de Assistência Técnica e Extensão Rural do Rio Grande do Sul (Emater/Ascar-RS).

O programa tem como objetivo promover a inserção social dos catadores de materiais recicláveis de Santa Maria/RS a partir da melhoria das condições de trabalho, geração de trabalho e renda e redução da insegurança habitacional, alimentar e nutricional. O Pisc também abrange a questão da identidade desses trabalhadores, que, ao não se reconhecerem como cidadãos, carecem de capital social para lutar contra a situação de exclusão na qual se encontram. A participação no programa dá aos beneficiários a possibilidade de transformar seu lugar simbólico na sociedade, por meio de uma mudança cultural. A identidade pode ser considerada

[...] o processo de construção de significado com base em um atributo cultural, ou ainda um conjunto de atributos culturais inter-relacionados, o(s) qual(ais) prevalece $(\mathrm{m})$ sobre outras fontes de significado (CASTELLS, 1999, p. 22).
O Pisc promove a integração de seus participantes, levando-os a uma atuação em uma práxis cotidiana voltada a interesses $e$ responsabilidades sociais mais amplas. Essas pessoas "acabam inseridas num processo de educação informal que contribui para a elaboração-reelaboração de culturas populares e a formação para a cidadania" (PERUZZO, 2002, p. 1). Dessa forma, em âmbito institucional, a articulação entre ensino, pesquisa e extensão pela universidade possibilita um enriquecimento na formação dos futuros profissionais. Além disso, potencializa a consciência socioambiental dos participantes do programa, promovendo visibilidade às ações que a instituição promove no intuito de aproximar-se cada vez mais da sociedade da qual faz parte.

\section{Percurso metodológico}

O Programa de inclusão social dos catadores de materiais recicláveis do Município de Santa Maria (RS) pela geração de trabalho e renda em economia solidária (Pisc) tem como percurso metodológico a pesquisa-ação para a realização das ações extensionistas. O programa leva em consideração a realidade local, bem como os interesses e necessidades relatados pelos catadores, pois

a pesquisa ação torna-se possível $e$ eticamente sustentável quando estão reunidas condições tais como: a iniciativa de pesquisa parte de uma demanda de pessoas ou grupos que não ocupam as posições de topo de poder, os objetivos são definidos com autonomia dos atores e com mínima interferência de membros da estrutura formal; todos os grupos sociais implicados no problema escolhido com o assunto da pesquisa são chamados para participar do projeto $e$ de sua execução e todos os grupos têm liberdade de expressão (THIOLLENT, 1988, p. 23). 
A pesquisa-ação, por meio de práticas extensionistas, permite a construção compartilhada do conhecimento em que os participantes, com o processo ensino-aprendizagem e saberes diferentes, trocam experiências, aprendem e ensinam por meio de práticas dialógicas. Peruzzo (2002) endossa a relevância dessa construção compartilhada, dizendo que é a partir da socialização do conhecimento individual e, também, acumulado com a prática cotidiana, que se promove a educação para a convivência social, a cidadania e para a formação de uma consciência de direitos e deveres.

A pesquisa avaliativa permeia todo o desenvolvimento das ações que vão sendo realizadas, com a participação das instituições e atores envolvidos e também dos beneficiários no caso, os catadores. Domingos (2000) enfatiza, argumentando que a participação de todos é de grande importância, contribuindo para atingir mais eficientemente os objetivos propostos, seja buscando a qualidade de vida ou a promoção da cidadania em setores específicos.

Com esse processo é possível repensar as situações vivenciadas, identificar os limites e reorientar as ações no sentido de se aproximar de uma prática compartilhada do conhecimento, o qual ocorre pelas relações estabelecidas entre os sujeitos sociais. A pesquisa avaliativa permite que a realidade vá, aos poucos, e com a inclusão de novos olhares, tomando novos contornos e se apresentando cada vez mais complexa. Essa necessidade de repensar o diagnóstico realizado refletiu-se na interdependência entre a identidade desses indivíduos e a sua prática em relação à transformação de sua realidade.

Berger e Luckmann (1985) argumentam que a relação entre o homem, como produtor, e o mundo social, como produto dele, é e permanece sendo uma relação dialética, uma vez que um atua reciprocamente sobre o outro. Ainda nessa mesma ideia,
A sociedade é uma realidade objetiva. O homem é um produto social. Torna-se desde já evidente que qualquer análise do mundo social que deixe de lado algum desses três momentos será uma análise distorcida (BERGER; LUCKMANN, 1985, p. 87-88).

Assim, Durkheim (apud KANAANE, 1994) evidencia a complexidade de se conhecer o todo, uma vez que os indivíduos associam-se formando a base da sociedade, cada um a partir de sua consciência individual, fundamentada em valores, normas e experiências. Daí advém a dificuldade, mas ao mesmo tempo a necessidade de explicar os fenômenos produzidos pelo todo a partir das características dessa totalidade, ou seja, do conhecimento dos fatos sociais pela sociedade.

Com essa consciência, o programa de extensão Pisc realizou reuniões com os diversos setores da sociedade que se envolvem com a temática urbano-social, propiciando uma articulação entre organizações e lideranças da comunidade, de entidades e de projetos que atuam com objetivos comuns, e do Poder Executivo Municipal, com a determinação de transformar a realidade social vivida pelos catadores. Parte-se do pressuposto que a responsabilidade pelo ambiente em que se vive é de todos; independentemente se indivíduos, organizações privadas ou públicas, a consciência social primeiramente deve partir e concretizar-se nas ações de cada cidadão, implicados em uma coletividade. Dessa forma, foram definidos alguns objetivos para o Pisc, como:

- realizar uma campanha institucional sobre coleta seletiva do lixo;

- organizar os catadores em associações ou cooperativas;

- desenvolver blocos de vedação, empregando garrafas pet, para a reutilização deste material em construção de moradias populares e comercialização pelas associações; 
- incentivar a prática de separação do lixo em condomínios, empresas (indústria, comércio e serviços), instituições de ensino, entidades de classe, clubes de serviços e outros;

- incentivar instituições beneficentes e famílias de catadores a desenvolver artesanato a partir de resíduos sólidos;

- promover a educação ambiental em escolas de ensinos fundamental e médio;

- fabricar um protótipo de um carro não motorizado para a coleta e a separação do lixo, ergonomicamente adequado à coleta seletiva e às condições de trafegabilidade do município de Santa Maria;

- desenvolver cursos de inclusão digital;

- promover maior integração entre a UFSM, esse segmento de público e as instituições participantes do programa;

- desenvolver nos alunos de graduação e pós-graduação a capacidade de identificar problemas relevantes à sua volta, avaliar diferentes posições quanto a esses problemas, conduzir sua postura de modo consciente e atuar na sociedade de forma transformadora.

\section{Relato de uma prática participativa}

Antes do início da intervenção extensionista, foi necessário verificar como se processava a dinâmica envolvendo os membros da comunidade. Primeiramente, realizaram-se algumas reuniões para conhecer melhor essa comunidade e para apresentar o motivo que levava aquelas pessoas a participar do programa. Esse momento também foi uma oportunidade para a comunidade manifestar seu interesse em questionar problemas comunitários e buscar alternativas para eles.

Após o conhecimento das demandas comunitárias, os extensionistas realizaram contatos com algumas lideranças municipais e todos foram convidados a participar do programa $e$ de sua execução. Os participantes do Pisc, juntamente com a comunidade atendida, definiram objetivos fundamentados nos problemas levantados e em ações para a viabilização das demandas sociais. A consciência da responsabilidade social se deu a partir do compartilhamento de saberes e experiências; os participantes relacionaram-se e atuaram na comunidade e sociedade visando a um bem-estar coletivo. O método de trabalho compartilhado e a percepção de que estavam participando de um processo de mútuo aprendizado foram fundamentais para a integração do grupo e o estabelecimento de objetivos.

Um permanente processo de avaliação constituiu parte essencial do desenvolvimento da experiência. A pesquisa participante exige um compromisso muito grande com as ações realizadas, pois cada atitude deve ser bem pensada e ter, de fato, um sentido. Estar atento a cada passo significou adotar uma atitude ética que sustentou todo o processo educativo, já que

a metodologia requerida para desenvolver a pesquisa aplicada deve oferecer subsídios para identificar e resolver problemas, inserir o conhecimento dos indivíduos e grupos na elaboração do conhecimento coletivo (THIOLLENT, 1988, p. 23).

À medida que o grupo, em face dos problemas levantados, sentia a necessidade de novos tipos de informações e outros conhecimentos técnicos, novos participantes foram sendo convidados para ingressar nesse processo. Acabou-se criando uma rede de solidariedade mútua, à qual cada ator social dedica seu tempo, seu conhecimento, suas expectativas e sua esperança de mudança em prol de uma ação social mais duradoura.

Destaca-se que essa integração de atores e saberes só se tornou possível a partir de uma automudança, rompendo com certos estereótipos que os faziam adotar uma postura elitista 
e sem possibilidade de enxergar os interesses da população excluída. Estudos indicam que a participação dos indivíduos deve ser construída dentro de uma dinâmica social mais ampla, visando a um desenvolvimento social, e que

tem o potencial, uma vez efetivada, de ajudar a mexer com a cultura, a construir e reconstruir valores, contribuir para maior consciência dos direitos humanos fundamentais e dos direitos de cidadania [...]. Revelam-se assim, como espaço de aprendizado das pessoas para o exercício de seus direitos e a ampliação da cidadania (PERUZZO, 2002, p. 9).

De acordo com alguns depoimentos, foi grande a satisfação pessoal com o trabalho de extensão, já que possibilitou a aplicabilidade das teorias aprendidas em sala de aula e a visualização dos resultados dos esforços investidos de forma mais direta e objetiva. Envolveu a pessoa com a realidade circundante, o que beneficia os envolvidos no programa não só pessoalmente como profissionalmente.

A interação entre as entidades e a comunidade resultou também em um aprendizado mútuo. Essa opção de método de trabalho teve como resultado o compartilhamento das responsabilidades sociais implícitas em qualquer projeto de educação e a vivência de possibilidades e situações clarificadoras do conceito de co-responsabilização de todos no processo de construção de uma nova ordem social que emerge atualmente.

\section{Discussões}

\subsection{Articulação entre ensino, pesquisa e extensão}

Por meio de discussões conjuntas, estudantes de graduação dos cursos de Comunicação Social - Relações Públicas, Publi- cidade e Propaganda e Jornalismo, Ciência da Computação, Artes Visuais, Desenho Industrial, Engenharia Mecânica e Engenharia Civil e de acadêmicos da pós-graduação dos Mestrados em Engenharia da Produção, Administração e Comunicação tiveram a oportunidade de não somente atuar junto a docentes em sua área específica. Destacou-se também a possibilidade de participarem de um trabalho interdisciplinar, na tentativa de compreender uma outra realidade e buscar soluções. Tal experiência certamente contribuiu para transformar uma realidade de saber compartimentado que muitas vezes caracteriza o meio acadêmico, no qual

há inadequação cada vez mais ampla, profunda e grave entre os saberes separados, fragmentados, compartimentados entre disciplinas e por outro lado, realidades ou problemas cada vez polidisciplinares, transversais, multidimensionais, transacionais, globais, planetárias (MORIN, 2001, p. 13).

Os discentes e docentes da UFSM envolvidos no programa passaram a entender que o desenvolvimento disciplinar das ciências provoca não apenas a "ignorância e a cegueira", mas o expert perde a aptidão de conceber o global e o fundamental, assim como o cidadão perde o direito ao conhecimento (MORIN, 2001, p. 15). Pode-se complementar dizendo que a universidade

não deve preocupar-se apenas em capacitar bons profissionais, pois concomitante a essa função deve ter o compromisso de proporcionar aos acadêmicos uma formação humanística habilitando-os como pessoas capazes de gerar transformações coerentes com a sua realidade de forma responsável e comprometida, ampliando, ao mesmo tempo, a sua visão e capacidade de reflexão (FOSSÁ; CARVALHO, 2004, p. 296). 
A ação interinstitucional entre Prefeitura Municipal de Santa Maria, por meio das Secretarias de Gestão Ambiental e de Cultura, Associação Sulina de Crédito e Assistência Rural Emater/Ascar-RS e UFSM demonstra que as organizações, sozinhas, pouco podem fazer em face do crescente número de problemas sociais, mas, quando unidas por objetivos comuns, podem transformar situações adversas. A mobilização de diversas frentes de atuação e diferentes competências possibilita a ampliação do debate sobre a responsabilidade social, porporcionando maior visibilidade $e$ impulsionando os meios de comunicação a mover a opinião pública, impulsão que se caracteriza pelo direito social à informação e à participação dos indivíduos (FLETA, 1995).

Da mesma forma, agrônomos, técnicos agrícolas, engenheiros civis, comunicadores e administradores envolvidos no programa perceberam que a interdisciplinaridade é o caminho para a construção de uma nova ordem social que emerge neste início de século. A interação entre as instituições e a comunidade envolvida resultou em diversas vantagens, proporcionou um aprendizado mútuo, possibilitou diferentes olhares sobre a realidade e a possibilidade de exercer atividades diferentes daquelas realizadas no cotidiano. Além de contribuir para o desenvolvimento de novas habilidades, a interdisciplinaridade favoreceu o desenvolvimento de redes de informações, o fortalecimento de relações interpessoais e o intercâmbio de conhecimentos técnicos e humanos.

Uma das realizações deste trabalho foi o desenvolvimento de blocos plásticos a partir de garrafas pet, com emprego da mão de obra dos próprios catadores na coleta das garrafas e na manufatura dos blocos.

Outra proposta realizada foi a inclusão digital dos catadores: cinquenta pessoas participaram de curso básico de informática (Windows, Word e Internet), com duração de 20 horas, ministrado pelos alunos do Grupo PET do Curso de Ciência da Computação da UFSM.

\subsection{A comunicação assumindo seu papel social}

Uma campanha de comunicação social foi planejada com o intuito de dar maior visibilidade ao problema do lixo em Santa Maria, promover a mudança de comportamento da sociedade e criar condições para a melhoria do trabalho do catador. Nesse sentido, buscou-se uma articulação com os meios de comunicação, os quais, por meio de seu papel social, podem contruibuir construindo significados e atuando na formação dos sujeitos sociais.

As ações foram desenvolvidas em dois bairros da cidade, que foram escolhidos por estarem na vizinhança da Associação dos Selecionadores de Materiais Recicláveis (Asmar). A realização da campanha envolveu atividades como planejamento e criação da identidade visual do Pisc (camisetas, flyers, cartazes, crachás, folders, ímãs de geladeira, banner, bonés), mascote do programa, certificados, jingle, comercial e vídeo institucional. A partir da criação da marca e dos materiais, foram realizadas palestras sobre a separação e a coleta seletiva do lixo em escolas de Ensino Médio, Fundamental e Superior.

Outra sugestão do programa foi a inclusão dessa temática no plano de ensino e a previsão de realização de oficinas de qualificação para os professores da rede pública de ensino sobre a problemática dos aterros sanitários, a falta de espaço para o lixo produzido diariamente, a coleta seletiva $e$ a inclusão social dos catadores, a compostagem, a incineração e a geração de energia. Ao mesmo tempo, foram realizados contatos com empresas, sensibilizando os empresários para a consciência ambiental. Os condomínios residenciais também foram sensibilizados por meio de panfletos entregues pelos próprios catadores da Asmar ajudando a divulgar a campanha. 


\section{Considerações finais}

São diversos os fatores que apontam para uma sociedade em crescente transformação, seres humanos cada vez mais desenvolvidos intelectualmente, a ciência em constante evolução, um número maior de bens e serviços ofertados priorizando o conforto e o bem-estar. Mas, paradoxalmente a essa "imagem" da evolução, assiste-se à produção de grandes quantias de lixo e resíduos, que a sociedade ainda não sabe como tratar adequadamente.

Segundo Morin e Kern (2003, p. 79), "o mito do desenvolvimento determinou a crença de que era preciso sacrificar tudo por ele." No entanto, os recursos naturais não podem mais ser vistos como meros objetos à disposição do ser humano. É importante perceber que essa problemática demanda, não só do poder público, mas de todos os cidadãos, a adoção de uma postura mais ativa e consciente de suas responsabilidades quanto aos hábitos de consumo. Sabe-se que essa problemática não é nova e o Pisc veio reforçar a necessidade de se pensar na reciclagem e na coleta seletiva como alternativas viáveis para superar-se a tradicional e simples prática do descarte.

No Brasil, a questão da desigualdade social não pode ser ignorada quando se trata de encontrar alternativas para um melhor aproveitamento dos recursos naturais, dos resíduos produzidos pelos próprios cidadãos e da mudança para um comportamento mais responsável socialmente. Tendo como suporte a metodologia da pesquisa-ação, buscou-se resgatar a emancipação social, produtiva e sustentável de um grupo de pessoas em situação de vida vulnerável e elevá-las a protagonistas de uma nova história e de um modelo social mais inclusivo.
Sabe-se que o atual cenário político, econômico e empresarial aponta para novos estilos de gestão, mais flexíveis e democráticos, o que, consequentemente, contribui para novas relações de trabalho. Portanto, a proposta que se lança é a de um novo modelo de distribuição de trabalho, renda e inclusão social, com vistas à sustentabilidade e melhoria da qualidade de vida de todos os cidadãos.

O programa também mostrou sua importância ao promover uma atuação integrada entre diferentes setores da sociedade $e$ da universidade. A ação interdisciplinar, tendo como eixo um programa de extensão, mostrou o quanto esse tipo de intervenção pode ter um papel importante na legitimação social da instituição universitária como promotora de bem-estar social.

Em outra ponta, ocorreu uma mobilização comunitária por meio da cooperação entre os sujeitos da transformação que se buscava. Toda a sociedade envolveu-se nesse inter-relacionamento, de forma solidária e organizada, possível graças à identificação entre indivíduos que têm uma história comum de problemas (GUSTIN, 2005). Afinal, uma sociedade que busca desenvolvimento não poderia fazê-lo em meio a uma massa de excluídos e não cidadãos (FERNANDES, 2000).

Por este relato de um projeto de extensão, denominado Pisc, pretendeu-se refletir acerca do papel que as instituições têm de estimular o acesso às informações e ao conhecimento, possibilitando a construção conjunta da realidade e a formação de cidadãos conscientes de sua responsabilidade plena, tendo como primeiro passo a consciência $e$ o respeito ao meio ambiente. 


\section{REFERÊNCIAS}

BERGER, Peter; LUCKMANN, Thomas. A construção social da realidade. 6. ed. Petrópolis: Vozes, 1985.

CASTELLS, Manuel. A sociedade em rede. São Paulo: Paz e Terra, 1999.

DOMINGOS, Armani. Como elaborar projetos? Guia prático para elaboração e gestão de projetos sociais. Porto Alegre: Tomo, 2000.

FELIX, R. A. Z. Coleta seletiva em ambiente escolar. Revista Eletrônica do Mestrado em Educação Ambiental, Rio Grande do Sul, v. 18, p. 56-71, 2007.

FERNANDES, Ângela. Responsabilidade social e a contribuição das relações públicas. Disponível em: < http:// www.portal-rp.com.br/bibliotecavirtual/responsabilidadesocial/0098.htm\#_edn5 > . Acesso em: 02/05/2009.

FLETA, Luis Solano. Fundamentos de las relaciones públicas. Madri: Sínteses, 1995.

FOSSÁ, Maria Ivete Trevisan. Inclusão social dos catadores de materiais recicláveis do Município de Santa Maria/RS/ Brasil pela geração de trabalho e renda em economia solidária. Programa de Apoio à Extensão Universitária voltado às políticas públicas - PROEXT 2005 - MEC/ SESu/DEPEM, Santa Maria, Universidade Federal de Santa Maria, 2006.

; CARVALHO, Clarissa Oliveira de. Comunicação, comprometimento e responsabilidade social na universidade. In: BARRICHELLO, Eugenia Mariano da Rocha (Org.). Visibilidade midiática legitimação e responsabilidade social. Santa Maria: Facos/UFSM, 2004.

GUSTIN, Miracy B. S. Resgate dos direitos humanos em situações adversas dos países periféricos. In: CONGRESSO DE FILOSOFIA DE DIREITO E FILOSOFIA SOCIAL, 22. Anais... Granada, 2005.

KANAANE, Roberto. Comportamento humano nas organizações - O homem rumo ao Século XXI. São Paulo: Atlas, 1994.

MORIN, Edgar; KERN, Anne Brigitte. Terra-pátria. 4. ed. Trad. Paulo Neves. Porto Alegre: Sulina, 2003.

A cabeça bem-feita: repensar a reforma, reformar o pensamento. Rio de Janeiro: Bertrand Brasil, 2001.

PERUZZO, C. M. K. Comunicação comunitária e educação para a cidadania. PCLA, Pensamento Comunicacional Latino Americano (Online), São Paulo, v. 4, n. 1, p. 1-10, 2002.

THIOLLENT, Michel. Metodologia da pesquisa-ação. 4. ed. São Paulo: Cortez; Autores Associados, 1988.

Texto recebido em 13 de novembro de 2009. Texto aprovado em 15 de janeiro de 2011. 